\title{
PROCALCITONIN, INTERLEUKIN-6 AND HIGH SENSITIVITY C REACTIVE PROTEIN IN THE EARLY PREDICTION OF NEONATAL SEPSIS, ARE THEY CORRELATED?
}

\author{
A. Abdollahi, A. Morteza, F. Nayyeri
}

Tehran University of Medical Sciences, Tehran, Iran

Introduction: We aimed to assess the value of simultaneous measurement of procalcitonin (PCT),interleukin-6 (IL-6) along with the other variables in the prediction of early neonatal sepsis.

Methods: We performed a follow up study on 95 neonates who were below $12 \mathrm{~h}$ age, had clinical signs of sepsis, or maternal risk factors of sepsis. Neonates were assigned to 4 groups including "proven early-onset sepsis", "clinical early-onset sepsis", "negative infectious status", and "uncertain infectious status". Blood samples were obtained within the first $12 \mathrm{~h}$ and repeated between 24 and $36 \mathrm{~h}$ of age for determination of PCT, IL-6, high sensitivity CRP (hs-CRP), and White blood cell count.

Results: Neonates with sepsis (uncertain sepsis, clinical sepsis and blood culture positive sepsis) had a higher WBC $(8.40 \pm 1.00$ vs. $16.59 \pm 0.73 ; \mathrm{p}<0.001)$, IL-6 (45.9 \pm 3.65 vs. $126.3 \pm 6.90, \mathrm{p}<0.001)$, PCT $(0.57 \pm 0.14$ vs. $2.800 \pm 0.45, \mathrm{p}<0.001)$ and hs-CRP $(2.22 \pm 0.27$ vs. $4.80 \pm 0.83, \mathrm{p}<0.001)$ levels than neonates without sepsis, when admitted to the hospital. This remained significant 12-24 hours after admission. Likewise patients with clinical evidence of sepsis had a higher serum IL-6 level compared to patients with uncertain sepsis on admission. They had higher serum PCT levels on the 12-24 hours of admission. Serum PCT levels were significantly correlated with serum IL-6 levels in patients with no sepsis and uncertain sepsis ( $\mathrm{r}=0.529, \mathrm{P}<0.05$ and $\mathrm{r}=0.521, \mathrm{P}<0.01$ respectively).

Conclusion: PCT is a good and efficacious serum marker in the prediction of early neonatal sepsis. Combination of IL-6, hs-CRP and PCT is a good marker for the prediction of neonatal sepsis. 